\title{
The Spirituality of Atheist and "No Religion" Individuals in the Millennial Generation: Developing New Research Approaches for a New Form of Spirituality
}

\author{
Samantha A. Bahan * \\ The University of Victoria \\ sbahan@uvic.ca
}

\begin{abstract}
As of 2011, those who identify as non-religious represented a portion of Canada's population 2.5 times larger than the combined total of those reporting as Muslim, Jewish, Buddhist, Sikh, and Hindu, with no indication that the rate of growth for this population is subsiding. Despite this growing population, religiously unaffiliated spiritual millennials are going undetected in the academic literature, and there is confusion between contemporary understandings of spirituality and religiousness for both researchers and millennials. Researchers seeking to understand the spiritual lives of millennials have typically assessed the growth of this movement by the number of individuals who identify as "spiritual but not religious," a phrase which emerged alongside the 1960s New Age movement to describe the so-called 'spiritual seekers.' This paper seeks to identify some of the sources of millennial spirituality, such as culture shifts during the 1960s and 70s and the secularization of the Canadian public education system, and to define a new form of spirituality unique to millennials. Alternative approaches to studying this group are proposed, and it is suggested that the phrase "spiritual but not religious" is no longer sufficient for understanding the spirituality of religiously unaffiliated individuals.
\end{abstract}

Keywords: Millennial spirituality; New Age movement; spiritual but not religious; secular spirituality.

\section{INTRODUCTION}

\begin{abstract}
A s of 2011, those who identify as non-religious represented a portion of Canada's population 2.5 times larger than the combined total of those reporting as Muslim, Jewish, Buddhist, Sikh, and Hindu, with no indication that the rate of growth for this population is subsiding. The growing number of individuals who identify as having "no religion" has promoted curiosity among researchers who want to understand the spiritual and religious lives of the millennial generation (Bryant, Choi, \& Yasuno, 2003; Smith \& Denton, 2005). Many young individuals who do not identify with traditional religion in any form experience spirituality in their lives (Bibby, Russell, \& Rolheiser, 2009). These people struggle to describe their experience due to a restricted vocabulary on the topic, and/or avoid identifying with the term "spiritual." This paper offers a closer look at the current rates of "spirituality" in millennials who say they are atheist

${ }^{*}$ I would like to thank Dr. Paul Bramadat for his ongoing and invaluable mentorship, support, and encouragement in my pursuit of a second undergraduate degree in religious studies. I would also like to thank Dr. Siobhan Chandler, whose kind words inspired the topic of this paper.
\end{abstract}


or that they have "no religion." Specifically, this paper will discuss some reasons why spiritual millennials are going undetected in the academic literature, the confusion between contemporary understandings of spirituality and religiousness for both millennials and researchers, as well as alternative approaches to studying this group. Overall, I want to suggest that the phrase "spiritual but not religious" is no longer sufficient for understanding the spirituality of religiously unaffiliated individuals.

\section{The Sources of Millennial Spirituality}

The growth of unchurched millennial spirituality can be traced to culture shifts in the 1960's, emphasizing values of pluralism, equality, diversity, and individual freedom (Chandler, 2008). These values were exemplified in political changes such as the 1982 Charter of Rights and Freedoms, and the secularization of Canadian education systems (Bramadat \& Seljak, 2008; Seljak, 2005). Many individuals of the Baby Boomer generation readily adopted these values, along with New Age religious ideas, which rejected the borders and dogma of traditional religion. The effects of these culture shifts have rippled into the millennial generation; the secularization of Canadian education systems, alongside religiously unaffiliated Baby Boomer parents, resulted in many individuals growing up without religion at home or school. Collectively, these factors have contributed to a substantial growth in the number of people who identify as atheist or nonreligious.

In addition to contributing to the growing population of religiously unaffiliated individuals, the effects of these culture shifts are also connected to a trend of religious illiteracy. While many millennials report that they are religiously unaffiliated, research has shown that some also report spirituality in their lives. However, a lack of exposure to various belief systems - as well as a perception that spirituality is inextricably intertwined with religion-has led to some confusion and vocabulary barriers for many young adults trying to articulate their spirituality. Furthermore, these barriers, in concert with questions reflecting a lack of clarity about how spiritual experiences should be understood and described, are resulting in these individuals going undetected in research seeking to understand millennial spirituality. Given the vast growth of those who identify as non-religious in North America over the past forty years, it is important to accurately study these individuals in order to understand what implications may stem from the growth of this population.

Although many millennials appear to experience and value some kind of "spirituality," the academic literature on this generation reflects a lack of clarity about a) how these experiences should be understood and described and $b$ ) how they might relate to or differ from those that researchers (and millennials) associate with "religion." This situation warrants a deeper reflection on the ways researchers have been analyzing these individuals and their spiritual practices, and points to the need for new research instruments to gather more accurate data about this movement. In an effort to do this, the remainder of this paper will first look at the growth of spiritual but religiously unaffiliated millennials, and some cultural and political distinctions between millennials in Canada and the USA. Following this, the role of Baby Boomer parenting practices and the secularization of the Canadian public education system in millennial's spiritual ambiguity will be discussed. Lastly, this paper will assess research challenges associated with the use of the New Age phrase "spiritual but not religious" as an umbrella term for studying religiously unaffiliated spirituality, and an alternative approach to studying the spirituality of millennials is proposed. 


\section{The Growth of Millennial Spirituality}

The growth of millennial spirituality is linked to the growing percentage of Canadians who say they have "no religion". Prior to 1971, less than 1\% of the Canadian population reported having no religion (Statistics Canada, 2001). By 1991, this rate had jumped to 12\%, and by 2001 it was $16 \%$, accounting for just under 4.8 million people in Canada. Forty percent of this group were aged 24 or under, with a median age of 31 years. This trend was most prominently seen in Western Canada, with residents in the Yukon Territory and British Columbia reporting "no religion" more frequently than any other response. Between 1991 and 2001, British Columbia saw a 39\% increase in residents who reported having no religion, accounting for more than a third of the provincial population. According to Canadian sociologist Reginald Bibby, surveys conducted on millennial teens in comparison to adult reports from the 2001 Census revealed the percentage of those who reported having no religion was greater for teens in every region of the country, with twice as many teens compared to adults reporting having no religion nationally (Bibby, Russell, \& Rolheiser, 2009). Between 2001 and 2011, the population of non-affiliated Canadians continued to grow, with approximately $23.9 \%$ of the Canadian population reportedly having no religion (Statistics Canada, 2011 National Household Survey). As of 2011, this group represented a portion of Canada's population 2.5 times larger than the combined total of those reporting as Muslim, Jewish, Buddhist, Sikh, and Hindu.

The increasing number of individuals who are religiously unaffiliated and experience spirituality has captured the interest of professionals in a range of areas related to science and particularly psychology (Culliford, 2011). The founding of such organizations as the Institute of Noetic Sciences in California in 1973 - inspired by a spiritual experience by Apollo 14 astronaut Edgar Mitchell - demonstrate a broadening of scientific inquiry to include often overlooked phenomena, such as the study of consciousness and its potential unknown capabilities. Furthermore, according to writer and psychotherapist Victor Schermer, the integration of spirituality into psychological theories regarding understanding the mind, and the practical application of this in therapeutic settings, is representative of a paradigm shift in the study of psychology (Culliford, 2011). These shifts represent how important the growth of millennial spirituality is becoming to a range of academic disciplines.

The decline of religion and the rise of spirituality is currently the topic of a lively debate among scholars, and multiple perspectives have been adopted to discuss the terms spirituality and religion. While the focus of this article is not to debate these terms, a clarification is helpful for the purposes of this paper. In accordance with dominantly held definitions, religion refers to historically consistent social systems and phenomena associated with doctrines, institutions, dogma, established rituals and traditions, and beliefs related to the afterlife which are usually about divinity (Bramadat, 2005; Bryant, Choi, \& Yasuno, 2003). Spirituality on the other hand, refers to a personal phenomenon-a set of qualities that may be cultivated that is not dependent on institutional settings such that an individual may experience a sense of healing, and or affirmation of the transcendent, their community, or themselves (Ammerman, 2013; Chandler, 2008; Culliford, 2011). Overall, academic literature on millennial spirituality has reflected a vague understanding of how best to study this topic, and how millennials relate to the concept of "spirituality."

Discrepancies about how to understand the terms "religious" and "spiritual" may contribute to teens' lack of ability to accurately reflect and describe their stance on spirituality and spiritual needs. According to sociologists of religion Bibby, Russell, and Rolheiser (2009), the number of teens identifying as atheist has jumped from $6 \%$ to $16 \%$ since the mid 1980 's, with fewer than half of all Canadian teens "definitely" believing in God as of 2008. Nonetheless, one in seven atheist youth and only $30 \%$ of teens with no religion reported having "spiritual needs" (Bibby, 2011). 
Conversely, Robert Wuthnow's research on the millennial generation in the United States reported that $60 \%$ of religiously unaffiliated millennials said "spiritual growth" was at least fairly important to them (2007). A longitudinal study of first year students from fifty colleges and universities across the United States found that, despite an increasing personal commitment to integrating spirituality into their lives over their first year in post-secondary, only $12 \%$ of those having no religious affiliation also identified as highly spiritual (Bryant et al., 2003).

Collectively, these studies suggest that a range of religiously unaffiliated millennials say they are spiritual, have spiritual needs, place importance on spiritual growth, or commit to integrating spirituality into their lives. The variety of these reports reflect the diverse and vague conceptualizations of "spirituality" held by both millennials and the researchers who are studying them. Before discussing further what millennial spirituality is, it is necessary to consider some important cultural variations that influence the experiences of religiously unaffiliated Canadian and American millennials.

\section{I. "No Religion" Millennials in the United States and Canada}

Describing millennial spirituality requires a brief discussion of the cultural and political differences between the United States and Canada, and how they influence the extent and implications of religious illiteracy and non-affiliation. Like Canada, the pattern of decline in religious affiliation has also been exhibited in the USA, but the influence of religion on American culture has remained quite prominent, as have the social repercussions of being nonreligious (Smith \& Denton, 2005). Throughout the USA, and particularly in the South and Midwest, attending religious services and belonging to a religious congregation are cultural norms. According to the National Study of Youth and Religion in the USA, teen popularity at school is significantly associated with attendance at religious services, with $15 \%$ of nonreligious American teens reporting that they have been made fun of or experienced at least a little pressure from their schoolmates for being religiously unaffiliated. The social acceptance of individuals identifying as nonreligious is quite different in Canada, particularly in provinces such as British Columbia where as many as one third of the provincial population reported having no religion as of 2011 (Statistics Canada, 2011 National Household Survey). Given these cultural differences, the trend of religious illiteracy and unaffiliation is likely less exaggerated in American millennials, for even those who were raised with little or no education about religion at school or at home most certainly still know peers with strong religious ties. In Canada, especially in urban areas of BC and other regions, this may not necessarily be the case.

Additionally, the social ramifications of non-religiosity are evident with regards to the role religion plays in the political arena (Wuthnow, 2007). In both Canada and the USA, religion plays an important role in how people evaluate political issues, movements, and candidates. According to Robert Putnam and David Campbell's book American Grace, the so-called culture wars that emerged in the post-1960s and gave rise to the surge of evangelical Protestant affiliation greatly benefitted the Republican party, who harnessed this opportunity with a call to return to "traditional family values" (Olson, 2012). The religious convictions of American voters consistently influence election outcomes, with regular church goers and evangelicals having generally favoured Republican candidates in all but one presidential election since 1968 (Wuthnow, 2007). Conversely, the growing population of frequently secular and religiously unaffiliated individuals has consistently demonstrated decreasing levels of support for Republican candidates, in opposition to the attitudinal uniformity of religious conservatives who are against abortion and same-sex marriage (Olson, 2012). Young Americans with various religious affiliations consider the mixing of politics and religion as acceptable, unlike non-religious individuals who tend to consider the mingling 
of these two to be unfavourable (Wuthnow, 2007). Given the differing cultural norms described between these two countries, it seems likely that all other things being equal, a religiously unaffiliated individual seeking political involvement will receive less support in the USA than in Canada.

Understanding the differences between Canada and the USA is important because much of the data discussed in this paper was gathered from studies conducted in the United States. This is quite simply because research on the spirituality of religiously unaffiliated millennials is currently more extensive in the USA than in Canada. Therefore, relating the findings of these studies to Canadian millennial spirituality, and the associated challenges of studying this population, requires careful consideration of the differences in cultural norms and religious illiteracy and unaffiliation between these two countries. In addition to these difficulties, other research challenges will now be discussed in greater depth, beginning with a closer reflection on two factors that have contributed to the spiritual ambiguity of religiously unaffiliated millennials.

\section{The Spiritual Confusion of Millennials}

Research investigating millennial spirituality has shown that many individuals of this generation are uncertain about how to describe and explain their "spirituality" and "spiritual" experiences. There are several contributions to this struggle, but two significant sources will be discussed here. The first, is the guidance (or lack thereof) provided by religiously unaffiliated Baby Boomer parents on religion and spirituality and the second, the secularization of Canadian education systems. This combination both limited their vocabulary and conceptual understanding of religion and spirituality and subsequently resulted in a trend of religiously illiterate and unaffiliated millennials.

The Baby Boomer generation gave rise to the counterculture of the 1960's (Chandler, 2010), of which a significant component was the rejection of restrictive dogmas associated with traditional religion in favour of a new spiritually awakened living - a trend recognized as the 'New Age' movement (Chandler, 2008). Some significant contributions to the cultivation of New Age spirituality included: Eastern religious teachings that emphasized individual enlightenment, the use of psychedelic drugs, and alternative medical practices focusing on holistic healing. Pluralism, equality, diversity, and individual freedom were values woven into the parenting practices of many Baby Boomers who, unlike their own parents, were less inclined to expose and involve their children in religious traditions and faiths (Bibby et al., 2009). Consequently, many millennials received passive guidance from parents, who actively chose to allow their children to independently explore religion and spirituality. The freedom to autonomously explore these areas appears to have been engaged to varying degrees by millennials growing up, and for some likely contributed to a sense of religious illiteracy.

This re-evaluation of traditional religion (mainly Christianity) led to a transformation of Canadian public education from predominantly Christian-based schools into a secular system in provinces across the country (Bramadat \& Seljak, 2008; Seljak, 2005). The implementation of the 1982 Charter of Rights and Freedoms provided grounds for legal actions such as the banning of religious instruction, exercises, festivities and practices from public secular classrooms. Furthermore, the legal removal of these religious components created ambiguity regarding the appropriateness of any discussion about religion, such as through religious studies, which is embraced or excluded to varying degrees across provinces, though it is not legally restricted. Thus, many children of the Baby Boomer generation also received little or no exposure to religion at school, contributing to a generation of religious illiteracy. For some, this absence of education about religion is noticed in post-secondary settings as well. In 1992, Sheridan and colleagues conducted 
a study that assessed the views of 328 clinical social workers, psychologists, and professional counselors; 83\% reported having received 'little' or 'no' training in religion and spirituality during graduate school (Starnino, 2002). Similar results were found in Canda and Furman's study in 1999 , which reported that of 1,069 social workers, $73 \%$ had received no instruction in their social work education on either religion or spirituality (Starnino, 2002). Furthermore, the majority of respondents in these studies reportedly felt ill-equipped to address religion and spirituality with clients, and believed more education on both of these topics was necessary (Starnino, 2002).

The culture shifts of the 1960's developed through the Baby Boomer generation, and ultimately immersed millennials in a secular culture that emphasized values which are incongruent with the principles of most traditional religions. These cultural changes were manifested in both home environments and school settings, leaving many millennials with significantly less knowledge about religion than their preceding generations. The effects of this can be seen in both the incredible growth of Canadians reportedly having no religion, and research reflecting a vague and limited understanding of the experiences and values of "spirituality" in the lives of millennials. The latter requires a deeper reflection on how these experiences might relate to or differ from the conceptualizations that we (and they) associate with "religion" and "spirituality."

\section{Millennial Spirituality: What is it?}

The historical conceptualization of individual pursuits and experiences of spiritual affirmation has always been inextricably intertwined with that of "religiousness," yet alongside the New Age movement emerged the phrase "spiritual but not religious" (SBNR) to describe the so-called "spiritual seekers." These individuals were characterized by a general resistance to and suspicion of committing to an organized religion, alternatively pursuing individualism and autonomy through selectively mixing and matching metaphysical beliefs, practices, and denominations from various religious traditions (Chandler, 2008; Fuller, 2001; Smith \& Denton, 2005). Since the 1960's, SBNR has become an umbrella term for spiritual individuals ranging widely in their association to "religion," with some affiliating or self-identifying with a traditional religion, and others opting for little or nothing to do with any form of organized religion (Chandler, CSRS public lecture, 2013). The concept of SBNR, as understood via "spiritual seekers" and New Age spiritual eclecticism, has served as the basis for many researchers interested in studying contemporary spirituality, acting as a form of relative measurement for how seriously or actively individuals are exploring their spirituality. However, millennials who have had little exposure to religion may be unfamiliar with the concept of SBNR, thus they may continue to associate the term 'spiritual' with 'religious' or something related to divinity, and in turn express hesitation identifying as "spiritual." For this reason, many religiously unaffiliated millennials who are 'spiritual' from an academic perspective, may be going undetected in research efforts.

This challenge is depicted by Smith and Denton (2005) who discussed the findings of the National Study of Youth and Religion (NSYR), considered to be the largest and most comprehensive study of American teens' religion and spirituality to date. To explore the category of religiously unaffiliated spiritual seekers, American teens across the country were asked about SBNR in an effort to detect whether they embraced the "spiritual but not religious" philosophy with the same enthusiasm and eclectic methods as had the preceding generation. The interviewers asked whether teens consider themselves to be "spiritual but not religious" and respondents were required to select from options of "very true," "somewhat true," "not at all true," or "don't know/refused." The results revealed that only $8 \%$ felt SBNR was very true for them, but $46 \%$ reported it as somewhat true. Another question asked about the inclusion of practices from a list of various religions into one's own spirituality, and the responses to these two questions were considered to 
depict the "trend" of SBNR in contemporary American teens. Smith and Denton interpreted these results to be most certainly inaccurate, on account of confusion about what the term SBNR meant based on their own experiences of interviewing hundreds of teens across the country. Of the interviews they had conducted, Smith and Denton noted that the vast majority reportedly had not heard of the phrase "spiritual but not religious," and even among those who had some familiarity, there was little meaning or understanding attached to it (2005). These responses were interpreted as clear indications of a lack of commitment to spiritual seeking relative to that observed with SBNR in the New Age movement.

While it is likely true that few millennials are spiritual seekers in the same manner as those in the New Age movement, to conclude that the population of young individuals who are spiritual yet nonreligious is declining would be inaccurate; the statistics described earlier demonstrate this growth. One could interpret the lack of spiritual eclecticism as spiritual "laziness," but it could also be that the form of "spirituality" many millennials are experiencing is quite different from that of past spiritual seekers, and therefore the methods through which they foster this "spirituality" or relate to the concept of "spirituality" would also be different. Overall, millennials are like their Baby Boomer parents in that they have a general resistance to and suspicion of committing to an organized religion, alternatively pursuing an individualistic endeavor which they only sometimes define as "spiritual." What the results of the NSYR indicate is that, at least in the United States, the phrase "spiritual but not religious" is no longer sufficient for understanding the spirituality of religiously unaffiliated individuals, largely because for many millennials, even "spirituality" has become an ambiguous concept.

\section{Why SBNR Inaccurately Describes Millennial Spirituality}

The challenge of understanding millennial spirituality was demonstrated in a longitudinal study that included over 3600 first year students in post-secondary school in the United States (Bryant et al., 2003). Students participated in both the 2000 Cooperative Institutional Research Program (CIRP) Freshman Survey, a four page questionnaire administered to American freshmen, and the 2001 Your First College Year Survey, administered at the end of freshmen year to follow-up the CIRP. Following the data collected from these surveys, this study explored the importance of religious and spiritual practices over the duration of these students' first year at school. Interestingly, the results found that the rate of students who self-reported as "highly spiritual" at the start of the school year decreased $4.2 \%$ by the end, whereas those who initially identified as "below average" or in the "lowest $10 \%$ " increased $5.4 \%$ by the spring. Additionally, the number of students who considered the integration of spirituality into their daily lives as "essential" or "very important" rose $5.6 \%$ and $4.5 \%$ respectively over the course of their first year in post-secondary school.

Furthermore, the majority of students involved in the study who reported being very spiritual were also very religious (also true for the reverse). For example, 38.1\% of highly spiritual individuals identified as being moderately religious and only $3.7 \%$ of individuals who reported being highly spiritual were not very religious. Thus the results revealed a significant overlap between spirituality and religiousness for the first year American post-secondary students who were surveyed. One interpretation of these results would be that the proportion of "no religion" first year students who are also highly spiritual is very minimal. However, an alternative interpretation could suggest that these results indicate a poorly articulated conceptual distinction between the terms "religious" and "spiritual," perhaps both on the part of the students responding and the researchers asking the questions. The latter was the interpretation taken by Bryant, Choi, and Yasuno (2003). They argued that the results revealed a clear sense of value associated with commitment to integrate spirituality into the lives of the participants, suggesting that SBNR as a 
basis for researching religiously unaffiliated spirituality may inaccurately articulate the kind of "spirituality" and spiritual practices experienced by millennials with no religion.

These studies suggest that the understanding of millennial spirituality may be currently unclear, with research findings turning up few individuals who self-identify as both very spiritual and religiously unaffiliated. Given the statistics reflecting a growing population of Canadians with spiritual needs but "no religion," it is clear that many millennials of this group are going undetected in the research. The phrase "spiritual but not religious," as understood from the New Age movement, is not sufficient for capturing and understanding the contemporary spirituality of millennials, possibly because some religiously unaffiliated individuals are not identifying with the term "spirituality." This may be more likely for Canadian millennials, who experience fewer social consequences than American millennials for rejecting concepts such as "religion" and "spirituality." If this is true, detecting this cohort of individuals will require efforts to enhance our understanding of the kind of "spiritualities" they are experiencing, and how it differs from prior conceptualizations in order to develop new research tools and gather more accurate data about this movement

\section{Research Going Forward}

Research instruments that more accurately articulate contemporary religiously unaffiliated "spirituality," would likely reveal less overlap between religious and spiritual self-identification. Developing such research instruments first requires an effort to better understand the various forms of "spirituality" and its social meaning in cultural and daily discourse; this was the goal of a recent study conducted by Ammerman (2013). Through the analysis of 330 texts of 95 participants in the forms of life history interviews, diary recordings, photo elicitation interviews and field notes, descriptions of spirituality and spiritual experiences were systematically grouped into four thematic categories. Ammerman identified four main discourses connected to the term SBNR. The first was the "Theistic Package" where spirituality is about God and one's relationship with God. The second was the "Extra-Theistic Package," which characterized a spirituality pertaining to an affective experience unrelated to divinity, explanation, or life after death. The third was "Ethical Spirituality," which is described as the single common denominator between the two prior packages, related to spiritual experiences encountered through helping others, overcoming ones' selfish needs to do what is morally right, and random acts of kindness. The last was "Belief and Belonging Spirituality," which referred to believing in God and belonging to a religious tradition. The packages that best explain millennials are the "Extra-Theistic Package" and "Ethical Spirituality," the former describing spiritual experiences as an interconnection with something beyond oneself, which could refer to a group or community, or something transcendent and extraordinary. This spirituality is rooted at the core of the self, and is experienced by way of seeking ones' individual life meaning, experiencing a meaningful life pattern, or encountering an awe evoking form of beauty through such things as art, music, or nature. These spiritual descriptors demonstrate a form of spirituality that has nothing to do with answering questions about death or an afterlife, a quality of millennial spirituality which has also been recognized in findings by Bibby et al. (2009). Therefore, their use would help overcome the challenges associated with using SBNR to identify the number of spiritual but religiously unaffiliated members of this generation in the academic literature.

The current limitations described above warrant further reflection on the development of new research instruments, such as survey or interview questions, which incorporate the unique challenges experienced by millennials with less knowledge about "religion" or "spirituality." The philosophy of monism may provide a framework for conceptualizing these questions. Unlike most 
religious traditions, which describe a dualistic theology that separates God from creation, monism as expressed in Buddhism describes a divinity within the individual and an interconnectedness of everything and everyone (Chandler, CSRS public lecture, 2013). Monism is a philosophy in which one is capable of experiencing wholeness or fulfilment in this lifetime, and that is inclusive of values such as diversity, autonomy, and equality. Given these qualities and its distinctiveness from the dominant philosophies of Western traditional religion, monism may resonate with millennials. A monist framework combined with descriptions of spirituality as explained in the "Extra-Theistic Package" (Ammerman, 2013), may be effective for developing questions to be used in new research instruments to study millennial spirituality. Moreover, millennials' struggle to conceptually dissociate the terms "spiritual" and "religious" from one another also needs to be considered for both the phrasing and order of questions. With these factors in mind, I will describe potential questions for a survey that could be used in future research seeking to understand "spirituality" as it is, and perhaps will be, experienced in the everyday lives of millennials and the generation that follows them.

Using the framework discussed above, the proposed survey will be broken into three sections, with the purpose of the questions for each section focusing on: 1) identification 2) emotions, practices and settings and 3) personal significance. Each section will consist of two types of items: statements which participants will respond to by selecting an option from "strongly agree", "somewhat agree," "don't know," "somewhat disagree" and "strongly disagree;" and an openended question to allow alternative responses not provided by the statement items. The first section will inquire about one's religious identification. Table 1. outlines examples questions in this section of the survey.

Table 1: Identification

\begin{tabular}{l}
\hline I identify as as a religious individual with a denomination such as: \\
- Protestant \\
- Catholic \\
- Jewish \\
- Muslim \\
- Buddhist \\
- Hindu \\
- Sikh \\
- Other religious tradition \\
\hline I identify as: \\
- having no religion \\
- atheist \\
- agnostic \\
\hline Open-ended: \\
Is there another way you would describe your religious identification that is not \\
included in the options here?
\end{tabular}

Questions of this nature will help clarify which individuals self-identify as non-religious, whereas the next sections will explore "spiritual" affective experiences and activities.

Section two of the survey is intended to help clarify whether and how participants feel or experience something spiritual, however, the items will not directly use the term "spiritual" in their content; this section is further separated into two subsections. Subsection one will focus on affective experiences, and subsection two will focus on the kinds of settings, objects, or activities that evoke this sense of connectedness. 
Table 2: Emotions, practices, and settings

\begin{tabular}{|c|c|}
\hline Subsection 1 \& Subsection 2 & \\
\hline $\begin{array}{l}\text { I think/believe in: } \\
\text { - an interconnectedness between all living things } \\
\text { - in a connection to something transcendent of myself } \\
\text { - in something bigger than myself }\end{array}$ & $\begin{array}{l}\text { I experience this feeling of connection when: } \\
\text { - I am in nature } \\
\text { - I experience or witness something I think is beautiful } \\
\text { - I spend time with people who are important to me } \\
\text { - I spend time with my pets }\end{array}$ \\
\hline $\begin{array}{l}\text { When I experience this feeling of connectedness } \\
\text { I feel a sense of: } \\
\text { - 'wholeness' within myself } \\
\text { - awe or wonder } \\
\text { - hope or comfort } \\
\text { - purpose } \\
\text { - meaning for my life }\end{array}$ & $\begin{array}{l}\text { - I listen to music } \\
\text { - I observe artwork } \\
\text { - I gaze at the stars } \\
\text { - I do yoga or meditation }\end{array}$ \\
\hline $\begin{array}{ll}\text { Open-ended: } & \text { Ope } \\
\text { Are there any other emotions you feel when you } & \text { Are } \\
\text { experience this feeling of connectedness that have } & \text { feeli } \\
\text { not been described above? } & \text { som }\end{array}$ & $\begin{array}{l}\text { n-ended: } \\
\text { there any other activities, settings, or things, that evoke a } \\
\text { ng of interconnectedness or personal connectedness to } \\
\text { ething greater than yourself? }\end{array}$ \\
\hline
\end{tabular}

The final section of the survey would inquire about the importance or value of these experiences for the participant, and how they relate these experiences to the term "spirituality" as they understand it.

Table 3: Personal Significance

I make an effort to foster this feeling of connectedness to something bigger than myself by:

- seeking experiences which evoke this feeling in me

- intentionally partaking in or going to a meaningful activity/setting when I feel stressed or

in despair

- doing at least one thing every day that evokes this feeling of connectedness Yes/No:

I personally identify as a spiritual person

The term 'spiritual' accurately describes my sense of connectedness to something bigger than myself

Open-ended:

If 'spiritual' is not an accurate term for the feeling of connectedness you

experience, why not?

Is there a different term or way you would describe this

experience for you?

These items are just examples for questions on this topic, but the format of this hypothetical survey requires further explanation.

Given that many millennials grew up without religion in their daily lives, many have a restricted vocabulary and conceptual framework from which they can draw from to make sense of and articulate their spiritual beliefs and experiences. The statement items are thus intended to provide a conceptual starting point for participants to reflect on their personal experiences throughout each section, priming them for their responses to the open-ended questions. Whereas the statement items provide the researcher with an idea of whether the description of "spirituality" as a feeling of 
connectedness with something beyond oneself, resonates with the experiences of the participants. Lastly, the open-ended questions provide further insight into other forms of spiritual experience in the lives of millennials, and ideas for revision of the research instrument. By asking questions in this way, it diverts the conception of "spirituality" away from its understanding as spiritual eclecticism and provides room for learning about alternative spiritual experiences or pursuits in the millennial generation. Studying this phenomenon with descriptive statements that do not directly refer to the terms "spiritual" or "spirituality" (though that is what is being investigated from the academic perspective), allows for the opportunity to hear from individuals who perhaps do not perceive these terms to be appropriate descriptors of their experience. Moreover, the responses to these statements and the follow-up question asking why the term "spiritual" might not be a good fit would potentially provide further clarification as to whether or not religiously unaffiliated spiritual millennials do actually identify as "spiritual," and if not, why not. The responses to the items described here would hopefully provide researchers with a more accurate orientation for conducting future research on religiously unaffiliated spiritual individuals.

The questions outlined above were described for use in a hypothetical survey. However, these questions could also be used in an interview setting, or as discussion points in workshops or focus groups. If the religious illiteracy described earlier in this paper is in fact a restrictive factor for millennials when reflecting on their religious and/or spiritual beliefs and experiences, the simplest way to alleviate these limitations is through thoughtful discussion on these topics. What is most important for future research on millennial spirituality is an open approach that provides an opportunity to hear about new forms of spirituality rather than limiting analyses to the contrasting categories of "religion" and "spirituality," not to mention the relative neologism of SBNR. It is possible that youth discourse is evolving such that discursive transitions between metaphors of "religion," "spirituality," and "SBNR" are no longer sufficient for capturing their "spiritual" experiences. For academics who would like a new metaphor for this group, I believe the idea of postmodern "secular spirituals" may be appropriate. This metaphor seeks to capture an individualistic pursuit of something transcendent of the self that is unrelated to concepts of "religion" and "spirituality." However, it is important to recall that these "spiritualities" have less to do with an identifiable label and more to do with a felt experience, which I would characterize as a secular transcendent interconnectedness. In other words, these experiences are defined by a sense of connectedness between the individual and something beyond the self that does not pertain to concepts of "religion" or divinity. Capturing these multidimensional experiences is even more challenging, given that they may vary not just between individuals but also within a single person, with the impact of the "spiritual" experience depending on the emotion it evokes, which depends on the situational context. For example, while one individual may experience a deep sense of oneness within themselves and everything around them through the practise of yoga, the person practising next to them may only mildly experience this, but alternatively feel a sense of wonder and interconnectedness with humanity when they witness a random act of kindness between strangers. Overall, more research in this area would provide opportunities for scholars to expand their own understanding of contemporary spirituality, and for millennials to reflect on the spirituality of their daily lives.

\section{CONCluding Remarks}

The New Age movement in the 1960's developed alongside cultural shifts that emphasized values of pluralism, equality, diversity and individual freedom. Concomitantly, many individuals coming of age during this movement came to adopt a hesitation and suspicion of adhering to traditional religions. This mentality was maintained to varying degrees when these individuals raised their 
own children, with some encouraging their children to question religious institutions while others provided more passive guidance on the task of spiritual or religious exploration. Upbringings of this nature in concert with the secularization of Canadian school systems resulted in a trend of religious illiteracy and significant contributions to the growth of the "no religion" population, from both the Baby Boomer and millennial generations. With this in mind, it is not surprising that millennials may be experiencing or relating to the concept of "spirituality" in a new way. The understanding of "spiritual but not religious" has evolved since its emergence in the New Age movement, and its prior conception is no longer sufficient for understanding or describing contemporary experiences of religiously unaffiliated spirituality. The historical association of spirituality with religion may mean that some teens and young adults are choosing to identify with neither of these terms. This is problematic for researchers seeking a deeper understanding of how millennials are experiencing spirituality. If these individuals are finding spiritual fulfillment in the absence of traditional religion, then it seems plausible that the growth of this population will not subside; understanding non-religious spirituality is essential for understanding the potential implications of this demographic in Canadian society. Therefore, I have suggested that future research on this population utilize research instruments that inquire about this phenomenon without directly incorporating the term "spiritual" into its questions. This approach will hopefully alleviate some of the confusion between differing understandings of "spirituality" by millennials and academics. Future research could seek to further develop a taxonomy for spirituality, explore the use of the alternative research approach described here with secondary and post-secondary students, and aim to promote or provide opportunities for further discussion and reflection on spirituality among millennials. Individual experiences related to religion and spirituality are changing, and thus the way we research religiously unaffiliated spirituality in the millennial generation must also change.

\section{REFERENCES}

Ammerman, N. T. (2013). Spiritual but not religious? Beyond binary choices in the study of religion. Journal for the Scientific Study of Religion, 52(2), 258-278. http://dx.doi.org/10.1111/jssr.12024

Bramadat, P. (2005). Beyond Christian Canada: Religion and ethnicity in a multicultural society. Religion and ethnicity in Canada, 1-29.

Bramadat, P., \& Seljak, D. (2008). Charting the new terrain: Christianity and ethnicity in Canada. Christianity and ethnicity in Canada, 2, 1.

Bibby, R. W., Russell, S., \& Rolheiser, R. (2009). The emerging millennials: How Canada's newest generation is responding to change and choice. Lethbridge, Canada: Project Canada Books.

Bibby, R. W. (2011). Beyond the Gods and back: Religion's demise and rise and why it matters. Lethbridge, Canada: Project Canada Books.

Bryant, A. N., Choi, J. Y., \& Yasuno, M. (2003). Understanding the religious and spiritual dimensions of students' lives in the first year of college. Journal of College Student Development, 44(6), 723-745. http://dx.doi.org/10.1353/csd.2003.0063

Chandler, S. (2008). The social ethic of religiously unaffiliated spirituality. Religion Compass, 2(2), 
240-256. http://dx.doi.org/10.1111/j.1749-8171.2007.00059.x

Chandler, S. (2010). Private Religion in the Public Sphere. Life Spirituality in Civil Society. In S.\& D. Houtman (Eds.), Religion of Modernity Relocating the Sacred to the Self and the Digital (pp. 69-88). Leiden/Boston: Brill.

Chandler, S. (2013, April 4). Spiritual but not religious: Navel gazing or a new paradigm for religious faith in modern times? [Video file]. Retrieved from http://vimeo.com/66026539

Culliford, L. (2011). The psychology of spirituality: An introduction. London, UK: Jessica Kingsley Publishers.

Fuller, R. C. (2001). Spiritual but not religious: Understanding unchurched America. Oxford: Oxford University Press. http://dx.doi.org/10.1093/0195146808.001.0001

Olson, L.R. (2012). Religion and American Public Life [Review of the book American grace: How religion divides and unites us]. Perspectives on Politics, 10(1), 103-106. http://dx.doi.org/10.1017/s1537592711004348

Seljak, D. (2005). Education, multiculturalism and religion. In P. Bramadat \& D. Seljak (Eds.), Religion and Ethnicity in Canada (pp. 178-200). Toronto, Canada: Pearson.

Smith, C. \& Denton, M. L. (2005). Soul searching: The religious and spiritual lives of American teenagers. New York, NY: Oxford University Press. http://dx.doi.org/10.1093/019518095x.001.0001

Starnino, V. (2002). textitReligion, spirituality, and social work education: Taking the next step. Retreived from ProQuest Dissertations \& Theses Global. (305505520).

Statistics Canada, 2011 National Household Survey, Statistics Canada Catalogue no. 99-D12X2011026. Retrieved from http://www12.statcan.gc.ca/nhs-enm/2011/dp-pd/dt-td/Direng.cfm

Statistics Canada Web Site. (2013) Retrieved March 22, 2014 from http:/ /www.statcan.gc.ca/

Wuthnow, R. (2007). After the baby boomers: How twenty-and thirty-somethings are shaping the future of American religion. Princeton, NJ: Princeton University Press. http://dx.doi.org/10.1515/9781400831227 